\title{
The economic impact of Marfan syndrome: a non-experimental, retrospective, population-based matched cohort study
}

\author{
Dmitrij Achelrod ${ }^{1 *}$, Carl Rudolf Blankart ${ }^{1}$, Roland Linder ${ }^{2}$, Yskert von Kodolitsch $^{3}$ and Tom Stargardt ${ }^{1}$
}

\begin{abstract}
Background: Marfan syndrome is a rare disease of the connective tissues, affecting multiple organ systems. Elevated morbidity and mortality in these patients raises the issue of costs for sickness funds and society. To date, there has been no study analysing the costs of Marfan syndrome from a sickness fund and societal perspective.

Objective: To estimate excess health resource utilisation, direct (non-)medical and indirect costs attributable to Marfan syndrome from a healthcare payer and a societal perspective in Germany in 2008.

Methods: A retrospective matched cohort study design is applied, using claims data. For isolating the causal effect of Marfan syndrome on excess costs, a genetic matching algorithm was used to reduce differences in observable characteristics between Marfan syndrome patients and the control group. 892 patients diagnosed with Marfan syndrome (ICD-10 Q87.4) were matched from a pool of 26,645 control individuals. After matching, we compared health resource utilisation and costs.

Results: From the sickness fund perspective, an average Marfan syndrome patient generates excess annual costs of $€ 2496$ compared with a control individual. From the societal perspective, excess annual costs amount to $€ 15,728$. For the sickness fund, the strongest cost drivers are inpatient treatment and care by non-physicians. From the sickness fund perspective, the third (25-41 years) and first (0-16 years) age quartiles reveal the greatest surplus in total costs. Marfan syndrome patients have 39\% more physician contacts, a 153\% longer average length of hospital stay, 119\% more inpatient stays, 33\% more prescriptions, 236\% more medical imaging and 20\% higher average prescription costs than control individuals. Depending on the prevalence, the economic impact from the sickness fund perspective ranges between $€ 24.0$ million and $€ 61.4$ million, whereas the societal economic impact extends from $€ 151.3$ million to $€ 386.9$ million.

Conclusions: Relative to its low frequency, Marfan syndrome requires high healthcare expenditure. Not only the high costs of Marfan syndrome but also its burden on patients' lives call for more awareness from policy-makers, physicians and clinical researchers. Consequently, the diagnosis and treatment of Marfan syndrome should begin as soon as possible in order to prevent disease complications, early mortality and substantial healthcare expenditure.
\end{abstract}

Keywords: Marfan syndrome, Economic impact, Cost-of-illness, Genetic matching, Administrative data

\footnotetext{
* Correspondence: dmitrij.achelrod@uni-hamburg.de

${ }^{1}$ Hamburg Center for Health Economics (HCHE), Universität Hamburg,

Esplanade 36, 20354 Hamburg, Germany

Full list of author information is available at the end of the article
} 


\section{Background}

Marfan syndrome is a rare, multisystem disease of the connective tissue, affecting multiple organ systems [1]. The prevalence is estimated at $1-3 / 10,000$ in both male and female individuals [2]. Although most Marfan syndrome patients inherit the disease through an autosomal dominant genetic pathway within the family, 20-30\% of new Marfan syndrome incidents are caused by de novo mutations in individuals with a previously unaffected family history [3,4]. Pathogenic mutations of the fibrillin-1 (FBN1) gene can cause dysregulation of transforming growth factor-beta 1 (TGF-b1) signalling, which is a polypeptide growth factor playing an important role in maintaining the integrity of the extracellular matrix. Consequently, excessive TGF-b1 causes a weakening of the tissues $[5,6]$.

Marfan syndrome primarily manifests itself through skeletal and ocular malformations, diseases of the skin and of the neurological system as well as lung and cardiovascular conditions $[7,8]$. Mitral valve prolapse and aneurysmal disease of the aorta can be diagnosed in up to 90\% [9-11] and $85 \%[9,12,13]$ of Marfan syndrome patients respectively. Aortic root dilation predisposes to severe chronic aortic regurgitation, aortic dissection and rupture [14]. Most systemic manifestations of the Marfan syndrome, especially cardiovascular ones, may appear in young individuals and are aggravated with increasing age as they are frequently the result of weakness in the connective tissue [15-17].

Thanks to the advancement in diagnostic techniques, such as non-invasive imaging technology and molecular genetic diagnostics $[8,18]$, as well as refined surgical techniques, such as the remodelling of the aortic root [19-22], Marfan syndrome can be diagnosed and treated at an early stage. These developments have contributed to rising life expectancy from 30 to 60 years within the last three decades [23-25]. However, the high cardiovascular risk may require life-long prophylactic medication with $\beta$-blockers $[24,26]$, angiotensin-converting enzyme inhibitors (ACE inhibitors) [5,8] or angiotensin receptor blockers (ARB) [7,27], as well as echocardiographic check-ups [28] and, if necessary, mitral valve replacement/remodelling [29,30] and aortic root surgery [31]. Permanent skeletal and ocular surveillance is also mandated [4,32,33].

Owing to increased Marfan syndrome-induced morbidity and mortality, Marfan syndrome patients require intensified utilisation of healthcare resources. Except for one study analysing one specific type of reimbursement of Marfan syndrome treatment in an outpatient clinic [34], there is no further evidence on the economic impact of Marfan syndrome. The authors are not aware of any nationwide study that analyses resource use across all healthcare sectors. Such studies, however, are crucial in shaping public health policy debates as they represent a valid economic basis for decision-makers, raise awareness and estimate the extent to which a disease has an impact on (a part of) society. They are regarded as an important tool in assisting policy planning, resource allocation, priority setting and can offer a basis for costeffectiveness analyses of healthcare interventions [35]. High disease costs might suggest, for instance, that more emphasis should be placed on prevention and curative interventions at an early stage of disease progression. Consequently, the aim of this paper is to comprehensively and reliably estimate health resource utilisation, direct (non-)medical and indirect costs attributable to Marfan syndrome from a sickness fund and a societal perspective in Germany.

\section{Methods}

\section{Study design and study sample}

In order to estimate the economic impact of the Marfan syndrome, a non-experimental, retrospective, populationbased matched cohort study design was applied. Costs for Marfan syndrome patients were compared with those of a matched cohort of patients not affected by the disease. The analysis is based on administrative claims data from Techniker Krankenkasse, Germany's second largest sickness fund (out of 221 sickness funds) covering about $9 \%$ of the German population in 2008, i.e. 7.6 million insurees. The dataset included longitudinal patient-level information on socio-demographic status, direct (non-)medical costs as well as on healthcare utilisation between 2006 and 2008, such as employment status, costs for outpatient/inpatient treatment or physician contacts.

We used a bottom-up, prevalence-based approach for cost estimation. For the Marfan syndrome group, patients were required to have one inpatient ICD-10-GM (German modification) Q87.4 diagnosis or at least two outpatient Q87.4 diagnoses within 180 consecutive days in 2006-2008 [36]. The control group was built by randomly selecting up to 150 male and 150 female nonMarfan syndrome insurees per each year of age ( 0 to 100 years) from the same database, i.e. 26,645 people.

Outcomes were measured in the observation period between 1 January 2008 and 31 December 2008. In order to allow for risk adjustment, a period of 365 days (1 January 2007 to 31 December 2007) prior to the index date (1 January 2008) was stipulated as the basis for determining patient-level risk profiles. For each patient, an ICD diagnosis was included in their risk adjustment if it was made at least once in inpatient settings or at least twice within 180 consecutive days in outpatient settings. Hence, applying equally to the case and control groups, individuals were excluded from the study if they had not been constantly enrolled during the risk adjustment and observation period. Patients who died during this time frame are exempted from this imperative. Data mining and cost analysis were conducted with $S A S 9.3$ (SAS Institute Inc.) and $R$ software respectively $[37,38]$. 


\section{Study outcomes}

Direct medical, direct non-medical and indirect costs were estimated from the sickness fund and the societal perspective. In order to achieve maximally transparent and comparable results, costs were structured following national standards into three distinct cost categories, 'direct medical', 'direct non-medical' and 'indirect costs' (see Table 1) [39].

\section{Direct medical costs}

First, direct medical costs are costs for inpatient/outpatient treatments, care by non-physicians (e.g. physiotherapy), pharmaceuticals, devices/medical appliances (e.g. prostheses), rehabilitation and medical services (e.g. home-based nursing care). Since the introduction of $\$ 116$ b Social Code Book (SGB) V in 2006, accredited hospitals can receive higher reimbursement prices for treating Marfan syndrome patients in an outpatient setting. Costs resulting from this funding scheme are described separately. To adjust direct medical costs for the societal perspective, co-payments for adult patients were added for outpatient consultations, pharmaceuticals, medical appliances, hospital stays and rehabilitations. According to the legislation, total annual co-payments were not allowed to exceed 1\% of annual gross income for chronically ill people and $2 \%$ of income for all residual insurees. We used average wages in 2008 (men: $€ 39,528$; women: $€ 31,932)$ [40] to calculate sex-adjusted co-payment thresholds according to $\$ 61$ SGB V. The value added tax (VAT) of $19 \%$ applicable to pharmaceuticals and medical appliances was excluded in the societal perspective. Adding investment costs to the tune of $4.7 \%$ [41] of inpatient treatment costs was necessary from the societal perspective to reflect the fact that hospital investments are tax funded.

\section{Direct non-medical costs}

Second, direct non-medical costs from the sickness fund perspective comprise administration costs, sick leave compensation paid by the sickness fund, travel expenses for physician appointments and ambulance transport as well as other non-medical services (e.g. housekeeping). Administration costs of $€ 192$ per insuree, based on the average administration costs of all German sickness funds, were applied [42].

Owing to the severe presentation of Marfan syndrome, affecting not only patients but probably also their relatives/partners [43], the cost of informal care by family caregivers was included in the societal perspective. For Marfan syndrome individuals under the age of 18 years, we assumed that at least one family member was caring for the person. Marfan syndrome patients over the age

Table 1 Cost categories from sickness fund and societal perspectives

\begin{tabular}{|c|c|c|}
\hline \multirow[t]{2}{*}{ Cost type } & \multicolumn{2}{|c|}{ Perspective } \\
\hline & Sickness fund & Societal \\
\hline \multicolumn{3}{|l|}{ Direct medical costs } \\
\hline Inpatient treatment & $\checkmark \mid \checkmark$ & $\checkmark \mid \boldsymbol{V}^{a}$ \\
\hline Outpatient treatment & $\checkmark \mid \checkmark$ & $\checkmark \mid \mathfrak{J}^{a}$ \\
\hline Care by non-physicians & $\checkmark \mid \checkmark$ & $\checkmark \mid \checkmark$ \\
\hline Pharmaceuticals & $\checkmark \mid \checkmark$ & $\checkmark \mid \boldsymbol{V}^{\mathrm{a}}$ \\
\hline Devices and medical appliances & $\checkmark \mid \checkmark$ & $\checkmark \mid \checkmark$ \\
\hline Rehabilitation & $\checkmark \mid \checkmark$ & $\checkmark \mid \checkmark$ \\
\hline Medical services (nursing care at home) & $\checkmark \mid \checkmark$ & $\checkmark \mid \checkmark$ \\
\hline \multicolumn{3}{|l|}{ Direct non-medical costs } \\
\hline Administration & $\checkmark \mid \checkmark$ & $\checkmark \mid \checkmark$ \\
\hline Sick leave compensation & $\checkmark \mid \checkmark$ & $x \mid x$ \\
\hline Travel expenses & $\checkmark \mid \checkmark$ & $\checkmark \mid \otimes)^{b}$ \\
\hline Other non-medical services & $\checkmark \mid \checkmark$ & $\sqrt{ } \mid \otimes{ }^{b}$ \\
\hline Informal care by family caregivers & $x \mid x$ & $\checkmark \mid \checkmark$ \\
\hline Patient time (loss of leisure time) & $x \mid x$ & $\checkmark \mid x$ \\
\hline \multicolumn{3}{|l|}{ Indirect costs } \\
\hline Reduced productivity at work & $x \mid x$ & $\checkmark \mid x$ \\
\hline Lost production (absence, disability, premature death) & $x \mid x$ & $\checkmark \mid \checkmark$ \\
\hline
\end{tabular}

The first sign reflects the relevance of the cost item from the respective perspective, whereas the second sign reflects whether the item is included in this analysis.

$\checkmark$ relevant | included; $\boldsymbol{x}$ not relevant | not included; $\mathrm{X}$ partially included.

${ }^{a}$ comprises patient co-payments in addition; ${ }^{b}$ only comprises costs borne by sickness fund. 
of 18 years were considered to receive informal care only if they were married or living with a partner (69.1\%) [44]. We did not incorporate care received from friends or other relatives. As the number of hours per day that carers spend with their Marfan syndrome-inflicted family member/partner is unknown, we used literature on family care for patients with heart diseases. Because of the severe cardiovascular disease of Marfan syndrome patients, we assumed that these patients require approximately the same amount of informal care as patients with a heart disease (8 hours per day, SD: 4.1 hours) [45]. In order to estimate the costs of informal care in the control group, we assumed that the multisystemic nature of Marfan syndrome, usually affecting more than two organs/parts of the body, is comparable to a health state of an individual with at least two distinct comorbidities. Control subjects who fulfilled the criteria for at least two Elixhauser comorbidity groups (measured by one binary variable per comorbidity class) [46] were presumed to require the same amount of care hours per day as Marfan syndrome patients. Subsequently, the carers' hours spent on informal care, for Marfan syndrome patients as well as for the control group, were valued at the average annual gross wage in $2008(€ 37,236)[40]$.

Sick leave compensations were excluded from the societal perspective as they denote a transfer payment.

\section{Indirect costs}

Being relevant from the societal perspective only, indirect costs consist of the cost of absence from work, the cost of premature death and the cost of reduced work productivity. The last factor could not be incorporated because our administrative data do not contain information about fluctuations in productivity. As recommended and widely applied $[39,47]$, patient-level indirect costs were measured using the human capital approach in the baseline scenario. In a secondary analysis, we used the friction cost model (see Table 2) [48].

The human capital approach measures production losses in terms of lost earnings: in our case, the number of sick leave days was multiplied by the average, sex-adjusted gross annual wage including employer contributions to social insurance in 2008 (men: €44,748; women: €36,144) [40]. Adjustments for workforce participation (proportion of a population in the active labour force) and employment rates were made. In the case of premature death, production losses were accumulated until the average retirement age of 65 years, adjusted for age- and gender-specific workforce participation/unemployment rates [49], survival probabilities [50], productivity growth $(0.5 \%)$ [51] and discounting (3\%) [52].

In contrast, the friction cost approach accounts for costs resulting from absence from work or premature mortality only during the time it takes to replace the missing worker. The time period until the worker is replaced is called the 'friction period' [48]. During the friction period itself (in Germany, 76 days [53]), the price of labour is not valued at $100 \%$ because internal workers can partially replace the missing individual and he/she can make up for the lost production on returning to work. Consequently, lost production was valued at $80 \%$ [48] when the absence from work was shorter than the average German friction period of 76 days [53]. If the absence from work was longer than this, productivity losses (at full value) were limited to 76 days, assuming that the worker had been completely replaced afterwards and the worker was not able to compensate for the forgone production. Premature death was treated as a fully valued productivity loss of a complete friction period.

In general, all (non-)medical and (in-)direct costs were winsorised (outliers are replaced by a specific percentile value) at their lowest 1st and highest 99th percentiles at cost category level in order to limit the distorting impact of outliers.

\section{Healthcare utilisation}

Indicators for healthcare resource utilisation were constructed, including physician contacts, length of hospital stays (LOS) and number of hospital stays, number and average cost of prescriptions, number of magnetic resonance (MRT)/computerised tomographies (CT) as well as number of sick leave days.

\section{Subgroup analysis and economic impact of Marfan syndrome}

Because disease manifestations and severity may progress throughout a patient's lifetime, costs may differ throughout the lifetime. To obtain a more granulated picture of the cost distribution, the analysis was stratified

Table 2 Overview of two approaches for measuring indirect costs

\begin{tabular}{|c|c|c|}
\hline & Human capital approach (baseline analysis) & Friction cost approach (sensitivity analysis) \\
\hline Perspective & $\begin{array}{l}\text { - considers patient's hours of work that are lost (possibly until } \\
\text { patient's retirement age) }\end{array}$ & $\begin{array}{l}\text { - considers patient's hours of work that are lost until employer can } \\
\text { replace the patient }\end{array}$ \\
\hline $\begin{array}{l}\text { Lost } \\
\text { production }\end{array}$ & $\begin{array}{l}\text { - measured through patient's lost earnings (valued at 100\%) } \\
\text { no cap on duration of absence from work }\end{array}$ & $\begin{array}{l}\text { - measured through patient's lost earnings (valued at 80\%) absence } \\
\text { from work capped at } 76 \text { days (friction period) }\end{array}$ \\
\hline $\begin{array}{l}\text { Premature } \\
\text { death }\end{array}$ & $\begin{array}{l}\text { - value of lost hours of work (=earnings) that would have } \\
\text { accumulated until patient's retirement age }\end{array}$ & $\begin{array}{l}\text { - value of lost hours of work (=earnings) + value of lost hours of work } \\
\text { for a full friction period (valued at 100\%) }\end{array}$ \\
\hline
\end{tabular}


into age quartiles of the examined Marfan syndrome population (I: 0-16 years, II: 17-24 years, III: 25-41 years, IV: $>41$ years).

We estimated the economic impact by multiplying the excess costs of Marfan syndrome by the number of diseased people in Germany. In addition to using prevalence rates obtained from our data, we used prevalence rates from the literature. According to international estimations, prevalence rates range from 1 [54] to 3 [2] per 10,000 .

\section{Statistical analysis}

The aim of this paper is to isolate the specific effect of Marfan syndrome on costs - the so-called 'average treatment effect on the treated' (ATT) [55]. However, observational studies may be subject to selection bias and to unbalanced population baseline characteristics because of a lack of randomisation. Thus, in order to reduce confounding due to unbalanced baseline characteristics between the Marfan syndrome patients and the control group as well as to determine the excess costs (ATT) of Marfan syndrome, 'genetic matching' (GM) was applied. GM is a multivariate algorithm that matches Marfan syndrome patients with their most similar control subjects on a set of observed covariates (e.g. age, sex, comorbidity). GM significantly improves the comparability of group baseline characteristics [56]. After GM, the difference in costs between the Marfan syndrome patients and the control group, i.e. excess costs, represents the effect specifically attributable to Marfan syndrome (ATT) [57].

Prior to applying GM, it is necessary to specify the covariates to match on. To minimise bias, we used a list of prespecified variables that are considered to possess a high prognostic potential for the outcome (cost). Evidence suggests that gender, age [58], comorbidities [46] and pharmacy-based metrics (PBM) [59] are robust predictors of healthcare costs. Consequently, in the matching procedure, the covariates were sex, age, 29 of the total 31 Elixhauser comorbidity groups $[46,60]$ and 30 of the total 32 PBM groups [59]. We excluded two Elixhauser comorbidity groups ('mitral valve disease', 'aneurysms') and two PBM groups ('blockers/calcium channel blockers', 'ACE inhibitors/angiotensin II antagonists') which are directly related to Marfan syndrome. All covariates were determined in 2007.

First, using a logistic regression, a propensity score (PS) [61] was obtained by combining the above-mentioned covariates (sex, age, 29 Elixhauser comorbidity groups and 30 PBM groups). Subsequently, a one-to-one GM was run to attain balance on the PS, age and sex (see Figure 1). We applied GM with replacement as it will generally achieve the best balance on covariates and the smallest conditional bias [57]. In order to compare the balance of covariates before

\section{Determine relevant covariates}

ELX groups, PBM groups, age, sex

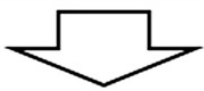

2. Run logistic regression to combine covariates into propensity score

Propensity Score (PS)

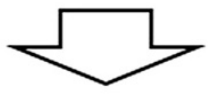

\section{3. one-to-one Genetic Matching on PS, age, sex to obtain matched pairs}

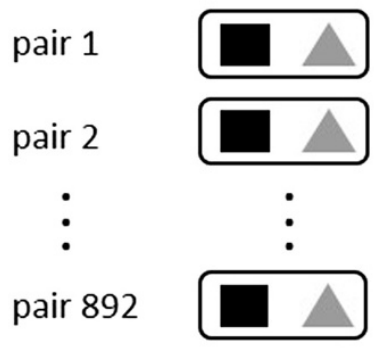
Marfan syndrome patient
Control patient

Figure 1 Overview of the steps in the statistical analysis/matching procedure.

and after matching, bootstrap Kolmogorov-Smirnov (KS) tests and empirical quantile-quantile (eQQ) statistics were calculated [62].

\section{Sensitivity and secondary analyses}

The statistical significance ( $\mathrm{p}$-values) of the matching results is only valid under the assumption that there are no unobserved confounders. Hence, Rosenbaum bounds were computed to estimate the impact of potentially existing hidden bias from unobserved covariates [63,64]. Rosenbaum bounds give an indication of how strong a hidden bias $(I)$ must be such that it changes the inference about the causal effects from the matching procedure [64]. In sum, a model is insensitive to hidden bias if its conclusions change for large values of $\Gamma$, whereas it is sensitive if its conclusions alter for values that are only slightly larger than $\Gamma=1$. 
To compare the baseline results with other methodological and structural specifications, three further analyses were conducted. First, we applied a pure PS model with the same parameterisations, but without the GM algorithm [65]. Second, the friction cost approach for estimating indirect costs was applied. Third, we carried out a sensitivity analysis on the lower-bound amount of hours for informal family care by subtracting one standard deviation from the mean $(8-4.1=3.9 \mathrm{~h} /$ day $)$.

\section{Results}

In total, 892 individuals with Marfan syndrome and 26,645 control subjects were included. The prevalence of Marfan syndrome was 1.17 per 10,000 individuals within the population of Techniker Krankenkasse. These 892 Marfan syndrome patients were matched one-to-one with 892 control individuals. Overall, the GM drastically reduced differences in all baseline covariates (see Table 3). The mean age of the control group was reduced from 50.50 years to 28.90 years, removing statistical difference to the Marfan syndrome group (28.95 years). Similarly, the predominance of males was diminished to $40.70 \%$ in order to adjust to the Marfan syndrome group. The difference in the PS between the groups was no longer statistically different from zero $(\mathrm{p}=0.999)$ after GM. Although the two groups had

Table 3 Baseline characteristics of the Marfan syndrome patients and control group and balancing tests pre and post genetic matching

\begin{tabular}{|c|c|c|c|c|}
\hline Variables & Marfan & Control & ${ }^{\text {a}}$ D-statistic & ${ }^{b}$ p-value \\
\hline \multicolumn{5}{|l|}{ Sample size (N) } \\
\hline before matching & 892 & 26,645 & - & - \\
\hline after matching & 892 & 892 & - & - \\
\hline \multicolumn{5}{|l|}{ Mean age (years) } \\
\hline before matching & 28.95 & 50.50 & 0.389 & $<0.001$ \\
\hline after matching & 28.95 & 28.90 & 0.002 & 0.996 \\
\hline \multicolumn{5}{|l|}{$\%$ female } \\
\hline before matching & 40.70 & 50.45 & - & $<0.001$ \\
\hline after matching & 40.70 & 40.70 & - & 1 \\
\hline \multicolumn{5}{|l|}{ Mean propensity score } \\
\hline before matching & 0.116 & 0.029 & 0.470 & 0.002 \\
\hline after matching & 0.116 & 0.116 & 0.002 & 0.999 \\
\hline \multicolumn{5}{|c|}{ Elixhauser comorbidities } \\
\hline before matching & \multicolumn{4}{|c|}{15 of 29 significantly different at $p<0.05$} \\
\hline after matching & \multicolumn{4}{|c|}{0 of 29 significantly different at $p<0.05$} \\
\hline \multicolumn{5}{|c|}{ Pharmacy-based classes } \\
\hline before matching & \multicolumn{4}{|c|}{16 of 30 significantly different at $p<0.05$} \\
\hline after matching & \multicolumn{4}{|c|}{0 of 30 significantly different at $p<0.05$} \\
\hline
\end{tabular}

${ }^{\mathrm{a}} \mathrm{D}$-statistic represents the maximum difference in the empirical cumulative distribution function (eQQ statistic).

${ }_{\mathrm{b}}^{\mathrm{p}}$-value: paired t-test for dichotomous and KS test for continuous variables. statistically significant differences (at $\mathrm{p}<0.05$ ) prior to matching in 15 of 29 Elixhauser groups, and in 16 of 30 PBM groups, the GM has removed all these divergences and has created a highly balanced distribution of clinical baseline characteristics (see Table 3 and Additional file 1: Table A1).

\section{Sickness fund perspective}

In both cost study perspectives, Marfan syndrome patients entail statistically significant higher costs (see Table 4). From the sickness fund perspective, an average Marfan syndrome patient generates higher direct medical costs $(€ 2330, \mathrm{p}<0.001)$ and greater direct nonmedical costs $(€ 167, \mathrm{p}<0.001)$ than an average nonMarfan syndrome patient, resulting in total excess expenditure of $€ 2496$ ( $\mathrm{p}<0.001)$. Inpatient treatment (38.4\%), care by non-physicians (33.8\%), outpatient visits $(10.7 \%)$ and pharmaceuticals (5.8\%) constitute the greatest share of the total difference. In our data, 28 patients were treated within the reimbursement framework of $\$ 116 \mathrm{~b}$ SGB V, which resulted in average costs of $€ 2954$ per patient per year. In total, the costs of medical services reimbursed through $\$ 116 \mathrm{~b}$ as a share of the cost of all hospital treatments was $6.9 \%$. Sick leave compensations represent the largest cost block in the direct non-medical costs with an excess of $€ 143$ ( $\mathrm{p}<0.001)$. These costs are directly related to the increased number of sick leave days taken by Marfan syndrome patients (9.23 vs. $5.02, \mathrm{p}<0.001)$.

\section{Societal perspective}

From the societal perspective, Marfan syndrome patients generate excess costs to the tune of $€ 15,728$ ( $\mathrm{p}<0.001)$. The surplus in direct medical costs $(€ 2366, \mathrm{p}<0.001)$ differs only slightly from the sickness fund perspective. However, excess direct non-medical costs are substantially higher at $€ 5875$ ( $\mathrm{p}<0.001)$ and represent $37.4 \%$ of the total excess costs. This is primarily caused by the introduction of costs for informal care by family caregivers $(€ 5851, \mathrm{p}<$ 0.001 ), which are considerably higher for the Marfan syndrome group (€7200) than for the control group (€1349). In addition, indirect costs for lost production come into play with a surplus of $€ 7487$ ( $p<0.001)$.

\section{Healthcare utilisation}

In terms of healthcare utilisation, Marfan syndrome patients had $38.8 \%$ more physician contacts $(\mathrm{p}<0.001)$, a $153.3 \%$ longer average length of stay if hospitalised $(\mathrm{p}<$ $0.001), 119.0 \%$ more inpatient stays ( $<<0.001), 33.4 \%$ more prescriptions $(\mathrm{p}<0.001), 236.3 \%$ more MRTs/CTs $(\mathrm{p}<0.001)$ and $19.7 \%$ higher average prescription costs than control individuals (see Table 4). 
Table 4 Average treatment effects for the treated (excess costs) in $€$ (per capita, in 2008)

\begin{tabular}{|c|c|c|c|c|c|c|c|c|c|c|}
\hline \multirow{3}{*}{ Direct medical costs } & \multicolumn{5}{|c|}{ Sickness fund perspective } & \multicolumn{5}{|c|}{ Societal perspective } \\
\hline & Marfan & Control & $\mathrm{ATT}^{\mathrm{a}}$ & & $\mathrm{Al} \mathrm{SE^{ \textrm {b } }}$ & Marfan & Control & $A T^{a}$ & & $\mathrm{AISE}$ \\
\hline & 4024 & 1695 & 2330 & $* * *$ & 273 & 4105 & 1739 & 2366 & $* * *$ & 278 \\
\hline Outpatient treatment & 780 & 512 & 268 & $* * *$ & 35 & 800 & 531 & 269 & $* * *$ & 35 \\
\hline Pharmaceuticals & 385 & 241 & 145 & $* *$ & 46 & 349 & 222 & 127 & ** & 39 \\
\hline Care by non-physicians & 1315 & 472 & 843 & $* * *$ & 163 & 1353 & 501 & 851 & $* * *$ & 165 \\
\hline Devices and medical appliances & 142 & 76 & 66 & $* * *$ & 18 & 122 & 65 & 57 & $* * *$ & 15 \\
\hline Inpatient treatment & 1337 & 379 & 958 & $* * *$ & 164 & 1413 & 403 & 1010 & $* * *$ & 173 \\
\hline Rehabilitation & 66 & 14 & 52 & $* * *$ & 15 & 67 & 14 & 53 & $* * *$ & 16 \\
\hline Medical services & $<1$ & 1 & -1 & & 5 & $<1$ & 1 & -1 & & 2 \\
\hline Direct non-medical costs & 392 & 226 & 167 & $* * *$ & 36 & 7431 & 1556 & 5875 & $* * *$ & 116 \\
\hline Administration & 192 & 192 & 0 & & 0 & 192 & 192 & 0 & & 0 \\
\hline Sick leave compensation & 161 & 18 & 143 & $* * *$ & 34 & $\mathrm{n} / \mathrm{a}$ & $\mathrm{n} / \mathrm{a}$ & $\mathrm{n} / \mathrm{a}$ & & $\mathrm{n} / \mathrm{a}$ \\
\hline Travel expenses & 39 & 15 & 24 & $* * *$ & 7 & 39 & 15 & 24 & $* *$ & 9 \\
\hline Other non-medical services & $<1$ & $<1$ & $<1$ & & $<1$ & $<1$ & $<1$ & $<1$ & & $<1$ \\
\hline Informal family care & $\mathrm{n} / \mathrm{a}$ & $\mathrm{n} / \mathrm{a}$ & $\mathrm{n} / \mathrm{a}$ & & $\mathrm{n} / \mathrm{a}$ & 7200 & 1349 & 5851 & $* * *$ & 116 \\
\hline Indirect costs & $\mathrm{n} / \mathrm{a}$ & $\mathrm{n} / \mathrm{a}$ & $n / a$ & & $n / a$ & 10,329 & 2842 & 7487 & $* * *$ & 718 \\
\hline Total costs & 4416 & 1920 & 2496 & $* * *$ & 286 & 21,865 & 6137 & 15,728 & $* * *$ & 824.4 \\
\hline \multicolumn{11}{|l|}{ Indicators for healthcare utilisation } \\
\hline Sick leave days & 9.23 & 5.02 & 4.21 & $* * *$ & 1.11 & & & & & \\
\hline Physician contacts & 10.11 & 7.28 & 2.83 & $* * *$ & 0.26 & & & & & \\
\hline Average length of stay & 3.06 & 1.21 & 1.85 & $* * *$ & 0.52 & & & & & \\
\hline Inpatient stays & 0.39 & 0.18 & 0.21 & $* * *$ & 0.04 & & & & & \\
\hline Prescriptions & 8.70 & 6.52 & 2.18 & $* * *$ & 0.49 & & & & & \\
\hline Average prescription cost & 27.58 & 23.04 & 4.55 & & 3.61 & & & & & \\
\hline MRT/CT imaging & 0.37 & 0.11 & 0.26 & $* * *$ & 0.05 & & & & & \\
\hline
\end{tabular}

average treatment effect for the treated represents excess resource utilisation attributable to Marfan.

${ }^{\mathrm{b}}$ Abadie-Imbens standard errors take the uncertainty of the matching process into consideration [57].

$*^{* *}<0.01{ }^{* * *}<0.001$

\section{Subgroup analysis}

Total costs per year of age from the sickness fund perspective are depicted in Figure 2. Because the frequency of Marfan syndrome patients in our study group below the age of 5 years and above the age of 60 years is low, as represented by the shaded area in the scatterplot, reliable estimates can be drawn only for age quartiles or for the population between the ages of 5 and 60 years. For instance, the great cost difference in children up to the age of 5 years results from three outliers that incurred exceptionally high costs for physiotherapy. The third age quartile (25-41 years) reveals the greatest surplus in total costs $(€ 2711)$, followed by the first $(0-16$ years, $€ 2322$ ) and fourth (>41 years, €2209) quartiles (see Additional file 1: Table A2). For quartile III, the main excess cost drivers are direct medical costs $(€ 2394)$ including inpatient treatment $(€ 1434)$, care by non-physicians $(€ 492)$ and outpatient visits $(€ 282)$. In the lowest age quartile (0-16 years), care by non-physicians $(€ 1061)$, inpatient $(€ 811)$ and outpatient treatments $(€ 222)$ are the major cost blocks of excess direct medical costs $(€ 2311)$. From the societal perspective, the second (1724 years: $€ 27,636)$ and third quartiles $(€ 15,146)$ cause the greatest excess expenditure. This is mainly a result of the high costs of lost production due to premature death in young to middle-aged individuals. Excess costs of informal care by family caregivers are highest in the youngest group (QI: €9121) because children receive more family care than middle-aged individuals according to our model specifications. However, no production losses accrue to children.

\section{Economic impact of Marfan syndrome}

Given a German population of 82.002 million in 2008 and depending on the prevalence rates $(1.17-3 / 10,000), 9600$ to 24,600 individuals are expected to have Marfan syndrome. Applying the cost data from our study, the overall cost of disease in 2008 from the sickness fund perspective ranged 


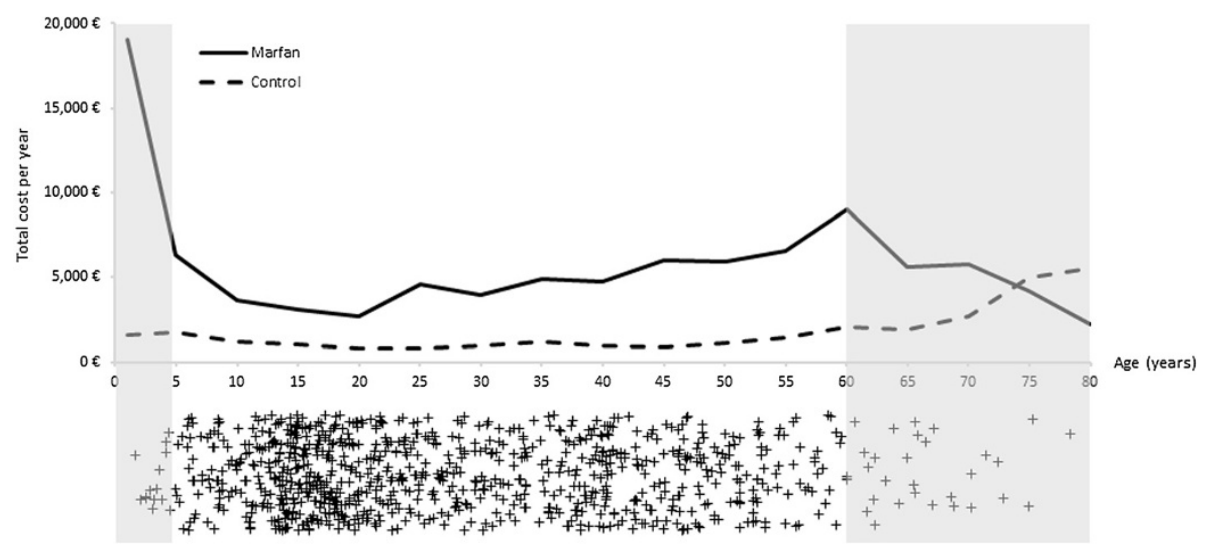

Figure 2 Total costs per capita for Marfan syndrome patients and control individuals, from the sickness fund perspective.

between $€ 24.0$ and $€ 61.4$ million, whereas the societal cost extended from $€ 151.4$ to $€ 386.9$ million.

\section{Results from sensitivity analysis}

The Rosenbaum bounds test reveals that our results are highly robust to potentially existing unobserved confounders (see Additional file 1: Table A3). The lower and upper p-value bounds show whether unobserved confounders of the magnitude $\Gamma$ have an influence on our results. For most outcome parameters, even a very strong hidden bias of the magnitude $\Gamma=3$ has no influence on the inference of the matching (at $\mathrm{p}<0.05$ ). Concerning pharmaceuticals, for instance, at a magnitude of bias of $\Gamma=2.5$, one would not be able to reject the hypothesis $(\mathrm{pU}=1)$ that unobserved covariates have an impact on the conclusions of the matching. Hence, at $\Gamma=2.5$, the excess drug costs might not be a causal effect of Marfan syndrome but possibly result from unobserved confounders.

Matching with a PS model instead of GM did not lead to substantially different results, showing that our model is robust to different specifications of the matching algorithm. As anticipated, replacing the human capital approach with the friction cost model to value the costs of lost production considerably reduced the excess indirect costs to $€ 359$ $(-95.26 \%)$, with highest excess values in the third age quartile (€999). Overall, the friction cost model yields an ATT of total costs of $€ 8599$, which is $44.24 \%$ lower than that in the baseline scenario (see Table 5).

Decreasing the amount of daily hours of family caregiving to $3.9 \mathrm{~h}$ diminished Marfan syndrome patients' excess costs for informal family care from $€ 5875$ to $€ 2852$ ( $\mathrm{p}<0.001)$. Consequently, the total societal cost difference amounted to $€ 12,729(\mathrm{p}<0.001)$ compared with $€ 15,728$ in the baseline scenario.

\section{Discussion}

To the knowledge of the authors, this is the first study worldwide to representatively examine the economic impact attributable to Marfan syndrome across in/outpatient sectors from a sickness fund and societal perspective with claims data. The analysis used a dataset with a large sample of insurees and a detailed account of costs and health resource utilisation. The demographic structure of the insurees in this dataset is representative of the overall German population [66]. A powerful matching algorithm ('genetic matching') was applied to balance observable confounders and to extract the causal effect of Marfan syndrome on costs. In contrast to other cost-of-illness studies, which simply total all medical or diagnosis-related costs without a comparison group, the reliability of our results is high because we identified the excess costs that are specifically attributable to Marfan syndrome [67].

From a sickness fund and societal perspective, the average excess expenditure per Marfan syndrome patient in 2008 was $€ 2496$ and $€ 15,728$ respectively. Costs mainly resulted from inpatient stays, care by non-physicians, outpatient treatments as well as informal family care and production losses in the societal perspective. Although Marfan syndrome patients required higher incremental drug expenditure (sickness fund: $€ 145$ ), the difference was not large because the most frequently applied pharmacological therapy for Marfan syndrome - beta-blockers [68] is relatively inexpensive.

Cost differences between Marfan syndrome and control subjects were highest in the third (25-41 years) and first (0-16 years) age quartiles from the sickness fund perspective. These results agree with the characteristics and progressive development of the disease. On the one hand, childhood and adolescence are regarded as the decisive period for the development of cardiovascular diseases in Marfan syndrome [69]. Hence, costs for Marfan syndrome patients in their early years of life may most likely be elevated because their diagnosis needs to be established using costly methods including $F B N 1$ gene sequencing, regular cardiovascular check-ups, ophthalmological care [8] and potentially life-long pharmacological therapy [1]. Their high 
Table 5 Sensitivity and secondary analyses with propensity score matching and friction cost model (values per capita in 2008)

\begin{tabular}{|c|c|c|c|c|c|}
\hline & \multirow{2}{*}{$\begin{array}{l}\text { Baseline (GM) } \\
\text { ATT }^{\mathrm{a}} \text { (in } € \text { ) }\end{array}$} & \multicolumn{2}{|c|}{ PS model } & \multicolumn{2}{|c|}{ Friction cost model } \\
\hline & & $\mathrm{ATT}^{\mathrm{a}}$ (in $€$ ) & $\%$ change $^{\mathbf{b}}$ & $\mathrm{ATT}^{\mathrm{a}}$ (in $€$ ) & $\%$ change $^{\mathbf{b}}$ \\
\hline \multicolumn{6}{|l|}{ Sickness fund perspective } \\
\hline Direct medical costs & 2330 & 2024 & -13.14 & 2330 & 0 \\
\hline Direct non-medical costs & 167 & 161 & -3.58 & 167 & 0 \\
\hline Total costs & 2496 & 2184 & -12.49 & 2496 & 0 \\
\hline \multicolumn{6}{|l|}{ Societal perspective } \\
\hline Direct medical costs & 2366 & 2059 & -12.97 & 2366 & 0 \\
\hline Direct non-medical costs & 5875 & 5790 & -1.44 & 5875 & 0 \\
\hline Indirect costs & 7487 & 7573 & 1.15 & 359 & -95.26 \\
\hline Total costs & 15,728 & 15,422 & -1.95 & 8599 & -44.24 \\
\hline
\end{tabular}

average treatment costs of the treated (ATT) represent excess costs attributable to Marfan.

bercentage change compared with baseline GM model.

costs of care by non-physicians can be explained by the need to treat skeletal malfunctions, such as physiotherapy for scoliosis or pectus deformities $[8,43,70]$. In addition, costs in the youngest quartile might be driven by newborns with the severe manifestation of the disease or by the neonatal Marfan syndrome [33]. Most of these infants have a life expectancy of less than 1 year of age and are highly treatment intensive [71]. On the other hand, patients in the third age quartile have to cope with symptoms of Marfan syndrome that have been aggravated over time. Cardiovascular manifestations often do not become overt and diagnosed until the third decade of life [10]. By that time, progressive aortic dilatation and aneurysms often dictate aortic and mitral valve surgery [68,72]. As shown in a recent meta-analysis, the mean age of Marfan syndrome patients undergoing cardiac surgery lies somewhere in their early/mid-thirties [14]. Our data corroborate this finding, indicating that inpatient stays, mostly because of cardiovascular surgeries, constitute $59 \%$ ( $€ 1434)$ of the excess direct medical costs in the third age quartile.

Owing to the systemic nature of their disease, Marfan syndrome patients require significantly more healthcare resources than control subjects, such as prescriptions, physician visits and inpatient stays/duration. Depending on the prevalence rate, the total economic impact ranges between $€ 24.0$ and $€ 61.4$ million (sickness fund perspective) and $€ 151.3$ and $€ 386.9$ million (societal perspective). Owing to the high number of sick leave days, Marfan syndrome has a considerable impact on employability.

Putting this study into the context of the scientific literature is challenging because, so far, very little evidence exists on the cost of illness of Marfan syndrome. Unrestricted comparisons cannot usually be made across different cost-of-illness studies on account of diverging methodologies [67], such as total cost vs. incremental/ excess cost studies. One German micro-costing study without a control group estimated that the average direct medical cost - measured by resource consumption - of treating a Marfan syndrome patient in their specialised outpatient clinic in 2008 amounted to $€ 389$ [34]. This figure is lower than our result (€780) because costs that accrued at other in/outpatient sites, such as expensive genetic testing, were not incorporated in that study [34]: in practice, however, the numerous morbidities of Marfan syndrome compel patients to see different in/outpatient specialist clinics, such as orthopaedics, ophthalmology and cardiology.

In terms of studies examining other rare diseases with a similar methodology, Blankart et al. (2013) [73] showed that costs attributable to chronic lymphocytic leukaemia (CLL) amounted to $€ 4946$ from a sickness fund perspective and $€ 7910$ from a societal perspective. In comparison with common chronic diseases, such as diabetes $(€ 19,677 \mathrm{~m}$ in 2010) [74], the attributable societal costs of Marfan syndrome are relatively low (€386 $\mathrm{m}$ in 2008) because of its rare occurrence (1-3/ 10,000). Nonetheless, considering that the costs and prevalence of Marfan syndrome constitute a fraction of $1.97 \%$ of the costs and $0.34 \%$ of the prevalence of diabetes $(890 / 10,000)$ [75], it becomes clear that the economic impact per Marfan syndrome patient is nearly six times higher than the impact per diabetes patient.

\section{Limitations}

We see four limitations to our study. First, although administrative data provide a comprehensive picture of healthcare costs and are increasingly recognised in health services and epidemiological research [76,77], our data do not provide any information on the clinical progression and/or severity of disease. For instance, neonatal Marfan syndrome or specific mutations in the FBN1 gene [12] may be more severe than other forms of Marfan syndrome, e.g. a manifestation of ectopia lentis and skeletal abnormalities. Consequently, healthcare resource utilisation and expenditure may vary 
according to disease severity. Costs at different developmental stages/severities of Marfan syndrome would be a factor worth considering in future research. Furthermore, our data do not include information about costs relating to public welfare budgets, such as costs for pension funds. Another pitfall of administrative data is the usage of the ICD catalogue, where some disorders similar to Marfan syndrome, such as the Shprintzen-Goldberg syndrome, may not be coded correctly because the current ICD classification includes only codes for about 500 out of the 8000 named rare diseases [78]. However, we believe that those ultra-rare diseases (estimated prevalence of ShprintzenGoldberg syndrome is less than 50 cases in Europe [79]), which might be coded incorrectly, do not substantially bias our results.

Second, although the costs of genetic testing for FBN1 mutations were included in the inpatient sector (through $\$ 116$ b reimbursement), it was not possible to account for them in the outpatient sector. Data coding modalities did not allow us to measure genetic testing costs for 20 Marfan syndrome patients. Such genetic testing, however, can be very expensive. Therefore, we might slightly underestimate outpatient treatment costs.

Third, we were not able to quantify intangible dimensions of indirect costs. For instance, Marfan syndrome patients face significant restrictions with respect to their quality of life, such as chronic pain [80] or psychological distress $[44,81]$, which may in turn affect productivity $[82,83]$. Similarly, because of an absence of information on treatment schedules/time spent coping with Marfan syndrome, patients' loss of leisure time was not included.

Finally, the inferences from the matching rely on the assumption that all relevant covariates have been included and that no unobserved confounders exist ('unconfoundedness assumption') [84]. This assumption is not empirically testable because hidden confounders cannot be measured. Nonetheless, one can assess the plausibility of the 'unconfoundedness assumption' by measuring the impact of the hypothetical existence of hidden confounders on the inferences, as we did using Rosenbaum bounds. Our results suggest that unconfoundedness is plausible because hidden bias $(I)$ had little impact on outcomes.

\section{Conclusion}

Relative to its low frequency, the treatment of Marfan syndrome requires high healthcare expenditure. Not only the high costs of Marfan syndrome but also its great burden on patients' lives call for more awareness from policy-makers, physicians and clinical researchers. Early diagnosis and prophylactic treatment may limit cardiovascular complications in particular and thus contain healthcare expenditure and patient morbidity. Use of health information technology, such as patient medical records, and enhanced coordination among healthcare providers across sectors might improve the medical management of rare diseases [85,86]. Finally, knowledge about the pathogenesis of the disease is increasingly being gained, and it is expected that the accomplishments of translational research in molecular biology will soon open a window of opportunity for treating most systemic manifestations of Marfan syndrome [24].

\section{Additional file}

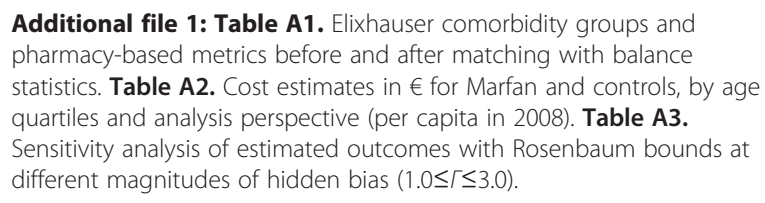

\section{Competing interests}

$\mathrm{RL}$ is employed by Techniker Krankenkasse, a large German sickness fund, and may have potential competing interests according to the guidelines of the International Committee of Medical Journal Editors. YK is the chairman of the non-profit patient advocacy organisation 'Marfan Hilfe e.V.'. DA, CRB, YK and TS declare that they have no competing interests.

\section{Authors' contributions}

CRB and TS collected the data. RL participated in the coordination of the data collection. DA, CRB, and TS developed the design of the study and performed the statistical analysis. DA, CRB, RL, YK and TS drafted the manuscript. All authors read and approved the final manuscript.

\section{Acknowledgements}

We are very grateful to Simon Frey who provided support for our statistical analysis.

\section{Author details}

${ }^{1}$ Hamburg Center for Health Economics (HCHE), Universität Hamburg, Esplanade 36, 20354 Hamburg, Germany. ${ }^{2}$ WINEG - Scientific Institute of the Techniker Krankenkasse (TK) for Benefit and Efficiency in Health Care, Bramfelder Str. 140, 22305 Hamburg, Germany. ${ }^{3}$ Department of Internal Medicine, Division of Cardiology, University Medical Center

Hamburg-Eppendorf, Martinistraße 52, 20246 Hamburg, Germany.

Received: 23 May 2014 Accepted: 17 June 2014

Published: 23 June 2014

\section{References}

1. Keane MG, Pyeritz RE: Medical management of Marfan syndrome. Circulation 2008, 117:2802-2813.

2. Judge DP, Dietz HC: Marfan's syndrome. Lancet 2005, 366:1965-1976.

3. Yetman AT, Bornemeier RA, McCrindle BW: Long-term outcome in patients with Marfan syndrome: is aortic dissection the only cause of sudden death? J Am Coll Cardiol 2003, 41:329-332

4. Yuan S-M, Jing H: Marfan's syndrome: an overview. Sao Paulo Med J 2010, 128:360-366.

5. Judge DP, Dietz HC: Therapy of Marfan syndrome. Annu Rev Med 2008, 59:43-59.

6. Neptune ER, Frischmeyer PA, Arking DE, Myers L, Bunton TE, Gayraud B, Ramirez F, Sakai LY, Dietz HC: Dysregulation of TGF-beta activation contributes to pathogenesis in Marfan syndrome. Nat Genet 2003, 33:407-411.

7. Bolar N, Van Laer L, Loeys BL: Marfan syndrome: from gene to therapy. Curr Opin Pediatr 2012, 24:498-504.

8. Loeys BL, Dietz HC, Braverman AC, Callewaert BL, De Backer J, Devereux RB, Hilhorst-Hofstee Y, Jondeau G, Faivre L, Milewicz DM, Pyeritz RE, Sponseller PD, Wordsworth P, De Paepe AM: The revised Ghent nosology for the Marfan syndrome. J Med Genet 2010, 47:476-485. 
9. Brown OR, DeMots H, Kloster FE, Roberts A, Menashe VD, Beals RK: Aortic root dilatation and mitral valve prolapse in Marfan's syndrome: an ECHOCARDIOgraphic study. Circulation 1975, 52:651-657.

10. Kiotsekoglou A, Sutherland GR, Moggridge JC, Nassiri DK, Camm AJ, Child $\mathrm{AH}$ : The unravelling of primary myocardial impairment in Marfan syndrome by modern echocardiography. Heart 2009, 95:1561-1566.

11. Rybczynski M, Bernhardt AMJ, Rehder U, Fuisting B, Meiss L, Voss U, Habermann C, Detter C, Robinson PN, Arslan-Kirchner M, Schmidtke J, Mir TS, Berger J, Meinertz T, von Kodolitsch Y: The spectrum of syndromes and manifestations in individuals screened for suspected Marfan syndrome. Am J Med Genet A 2008, 146A:3157-3166.

12. Faivre L, Collod-Beroud G, Loeys BL, Child A, Binquet C, Gautier E, Callewaert B, Arbustini E, Mayer K, Arslan-Kirchner M, Kiotsekoglou A, Comeglio P, Marziliano N, Dietz HC, Halliday D, Beroud C, Bonithon-Kopp C, Claustres M, Muti C, Plauchu H, Robinson PN, Adès LC, Biggin A, Benetts B, Brett M, Holman KJ, De Backer J, Coucke P, Francke U, De Paepe A, et al: Effect of mutation type and location on clinical outcome in 1,013 probands with Marfan syndrome or related phenotypes and FBN1 mutations: an international study. Am J Hum Genet 2007, 81:454-466.

13. Marsalese DL, Moodie DS, Vacante M, Lytle BW, Gill CC, Sterba R, Cosgrove DM, Passalacqua M, Goormastic M, Kovacs A: Marfan's syndrome: natural history and long-term follow-up of cardiovascular involvement. J Am Coll Cardiol 1989, 14:422-428. discussion 429-431.

14. Benedetto U, Melina G, Takkenberg JJM, Roscitano A, Angeloni E, Sinatra R: Surgical management of aortic root disease in Marfan syndrome: a systematic review and meta-analysis. Heart 2011, 97:955-958.

15. Chow K, Pyeritz RE, Litt HI: Abdominal visceral findings in patients with Marfan syndrome. Genet Med 2007, 9:208-212.

16. Détaint $D$, Faivre L, Collod-Beroud G, Child AH, Loeys BL, Binquet $C$, Gautier E, Arbustini E, Mayer K, Arslan-Kirchner M, Stheneur C, Halliday D, Beroud C, Bonithon-Kopp C, Claustres M, Plauchu H, Robinson PN, Kiotsekoglou A, De Backer J, Adès L, Francke U, De Paepe A, Boileau C, Jondeau G: Cardiovascular manifestations in men and women carrying a FBN1 mutation. Eur Heart J 2010, 31:2223-2229.

17. Jondeau G, Michel JB, Boileau C: The translational science of Marfan syndrome. Heart 2011, 97:1206-1214.

18. De Paepe A, Devereux RB, Dietz HC, Hennekam RC, Pyeritz RE: Revised diagnostic criteria for the Marfan syndrome. Am J Med Genet 1996, 62:417-426.

19. Silverman DI, Burton KJ, Gray J, Bosner MS, Kouchoukos NT, Roman MJ, Boxer M, Devereux RB, Tsipouras P: Life expectancy in the Marfan syndrome. Am J Cardiol 1995, 75:157-160.

20. Gott VL, Greene PS, Alejo DE, Cameron DE, Naftel DC, Miller DC, Gillinov AM, Laschinger JC, Borst HG, Cabrol CEA, Cooley DA, Coselli JS, David TE, Griepp RB, Kouchoukos NT, Turina MI, Pyeritz RE: Replacement of the aortic root in patients with Marfan's syndrome. N Engl J Med 1999, 340:1307-1313.

21. Kallenbach K, Karck M, Leyh RG, Hagl C, Walles T, Harringer W, Haverich A: Valve-sparing aortic root reconstruction in patients with significant aortic insufficiency. Ann Thorac Surg 2002, 74:S1765-S1768. discussion S1792-1799.

22. Bernhardt AMJ, Treede H, Rybczynski M, Sheikzadeh S, Kersten JF, Meinertz $\mathrm{T}$, von Kodolitsch $Y$, Reichenspurner $\mathrm{H}$ : Comparison of aortic root replacement in patients with Marfan syndrome. Eur J Cardiothorac Surg 2011, 40:1052-1057.

23. Murdoch JL, Walker BA, Halpern BL, Kuzma JW, McKusick VA: Life expectancy and causes of death in the Marfan syndrome. N Engl J Med 1972, 286:804-808.

24. Pyeritz RE: Marfan syndrome: 30 years of research equals 30 years of additional life expectancy. Heart 2009, 95:173-175.

25. Silverman DI, Gray J, Roman MJ, Bridges A, Burton K, Boxer M, Devereux RB, Tsipouras P: Family history of severe cardiovascular disease in Marfan syndrome is associated with increased aortic diameter and decreased survival. J Am Coll Cardiol 1995, 26:1062-1067.

26. Ladouceur M, Fermanian C, Lupoglazoff J-M, Edouard T, Dulac Y, Acar P, Magnier S, Jondeau G: Effect of beta-blockade on ascending aortic dilatation in children with the Marfan syndrome. Am J Cardiol 2007, 99:406-409.

27. Lacro RV, Dietz HC, Wruck LM, Bradley TJ, Colan SD, Devereux RB, Klein GL, Li JS, Minich LL, Paridon SM, Pearson GD, Printz BF, Pyeritz RE, Radojewski E, Roman MJ, Saul JP, Stylianou MP, Mahony L, Pediatric Heart Network Investigators: Rationale and design of a randomized clinical trial of beta- blocker therapy (atenolol) versus angiotensin II receptor blocker therapy (losartan) in individuals with Marfan syndrome. Am Heart J 2007, 154:624-631.

28. Aldrich HR, Labarre RL, Roman MJ, Rosen SE, Spitzer MC, Devereux RB: Color flow and conventional echocardiography of the Marfan syndrome. Echocardiography 1992, 9:627-636.

29. Settepani F, Szeto WY, Pacini D, De Paulis R, Chiariello L, Di Bartolomeo R, Gallotti R, Bavaria JE: Reimplantation valve-sparing aortic root replacement in Marfan syndrome using the Valsalva conduit: an intercontinental multicenter study. Ann Thorac Surg 2007, 83:S769-S773. discussion S785-790.

30. Bernhardt AM, Treede H, Detter C, Rybczynski M, Sheikhzadeh S, Wagner FM, Von Kodolitsch Y, Reichenspurner H: Results of modern mitral valve repair in patients with Marfan syndrome. Thorac Cardiovasc Surg 2014, 62:35-41.

31. LeMaire SA, Carter SA, Volguina IV, Laux AT, Milewicz DM, Borsato GW, Cheung CK, Bozinovski J, Markesino JM, Vaughn WK, Coselli JS: Spectrum of aortic operations in 300 patients with confirmed or suspected Marfan syndrome. Ann Thorac Surg 2006, 81:2063-2078. discussion 2078.

32. Peters KF, Horne R, Kong F, Francomano CA, Biesecker BB: Living with Marfan syndrome II. Medication adherence and physical activity modification. Clin Genet 2001, 60:283-292.

33. Von Kodolitsch $Y$, Robinson PN: Marfan syndrome: an update of genetics, medical and surgical management. Heart 2007, 93:755-760.

34. Manow M-L, Paulsen N, Rybczynski M, Mir T, Bernhardt AMJ, Treede H, Ohm G, Fuisting B, Rehder U, Meier F, Vogler M, Meinertz T, Overlack K, von Kodolitsch Y: [Analysis of costs and profits of ambulatory care of Marfan patients after initiation of a novel German legal directive (116 b SGB V)]. Med Klin (Munich) 2010, 105:529-537.

35. Rice DP: Cost of illness studies: what is good about them? Inj Prev 2000, 6:177-179.

36. Roll K: The influence of regional health care structures on delay in diagnosis of rare diseases: the case of Marfan syndrome. Health Policy 2012, 105:119-127.

37. Sekhon JS: Multivariate and propensity score matching software with automated balance optimization: the matching package for R. J Stat Software 2011, 42:1-52

38. Mebane WR, Sekhon JS: Genetic optimization using derivatives: the rgenoud package for R. J Stat Software 2011, 42:1-26.

39. IQWIG Institut für Qualität und Wirtschaftlichkeit im Gesundheitswesen: Working Paper Cost Estimation (Version 1.0). 2009. https://www.iqwig.de/ download/Working_Paper_Cost_Estimation.pdf.

40. Statistisches Bundesamt: Entwicklung der Bruttoverdienste. Bonn: Statistisches Bundesamt; 2008.

41. Deutsche Krankenhausgesellschaft (German Hospital Association): Krankenhausstatistik. 2008. www.dkgev.de/media/file/5776.Anlage_1.pdf.

42. Statistisches Bundesamt: Gesundheitsausgabenrechnung. Bonn: Statistisches Bundesamt; 2008.

43. Peters KF, Kong F, Horne R, Francomano CA, Biesecker BB: Living with Marfan syndrome I. Perceptions of the condition. Clin Genet 2001, 60:273-282.

44. De Bie S, De Paepe A, Delvaux I, Davies S, Hennekam RCM: Marfan syndrome in Europe. Community Genet 2004, 7:216-225.

45. Magliano L, Fiorillo A, De Rosa C, Malangone C, Maj M, National Mental Health Project Working Group: Family burden in long-term diseases: a comparative study in schizophrenia vs. physical disorders. Soc Sci Med 2005, 61:313-322.

46. Elixhauser A, Steiner C, Harris DR, Coffey RM: Comorbidity measures for use with administrative data. Med Care 1998, 36:8-27.

47. Liljas B: How to calculate indirect costs in economic evaluations. Pharmacoeconomics 1998, 13(1 Pt 1):1-7.

48. Koopmanschap MA, Rutten FF, van Ineveld BM, van Roijen L: The friction cost method for measuring indirect costs of disease. $J$ Health Econ 1995, 14:171-189.

49. Institut für Arbeitsmarkt- und Berufsforschung (IAB): Projektion des Erwerbspersonenpotenzials bis 2050 - Annahmen und Datengrundlage. Ergebnisse aus der Projektarbeit des Instituts für Arbeitsmarkt- und Berufsforschung. Nürnberg: Institut für Arbeitsmarkt- und Berufsforschung (IAB); 2005. Forschungsbericht Nr. 25/2005].

50. Statistisches Bundesamt: Bevölkerung und Erwerbstätigkeit - Sterbetafel Deutschland 2009/11. Wiesbaden: Statistisches Bundesamt; 2013.

51. Statistisches Bundesamt: Reallöhne, Nettoverdienste - Reallohnindex Wiesbaden: Statistisches Bundesamt; 2013. 
52. Smith $\mathrm{DH}$, Gravelle $\mathrm{H}$ : The practice of discounting in economic evaluations of healthcare interventions. Int J Technol Assess Health Care 2001, 17:236-243.

53. Heckmann M, Kettner A, Rebien M: Offene Stellen im N. Quartal 2008 Einbruch in der Industrie - Soziale Berufe Legen Zu. Nürnberg: [IABKurzbericht: Aktuelle Analysen und Kommentare aus dem Institut für Arbeitsmarkt- und Berufsforschung]; 2009.

54. Gray JR, Bridges AB, Faed MJ, Pringle T, Baines P, Dean J, Boxer M: Ascertainment and severity of Marfan syndrome in a Scottish population. J Med Genet 1994, 31:51-54.

55. Imbens GW: Nonparametric estimation of average treatment effects under exogeneity: a review. Rev Econ Stat 2004, 86:4-29.

56. Diamond A, Sekhon JS: Genetic matching for estimating causal effects: a general multivariate matching method for achieving balance in observational studies. Rev Econ Stat 2012, 95:932-945.

57. Abadie A, Imbens GW: Large Sample properties of matching estimators for average treatment effects. Econometrica 2006, 74:235-267.

58. Bertakis KD, Azari R: Patient gender differences in the prediction of medical expenditures. J Womens Health (Larchmt) 2010, 19:1925-1932.

59. Kuo RN, Dong Y-H, Liu J-P, Chang C-H, Shau W-Y, Lai M-S: Predicting healthcare utilization using a pharmacy-based metric with the WHO's Anatomic Therapeutic Chemical algorithm. Med Care 2011, 49:1031-1039.

60. Quan H, Sundararajan V, Halfon P, Fong A, Burnand B, Luthi J-C, Saunders $L D$, Beck CA, Feasby TE, Ghali WA: Coding algorithms for defining comorbidities in ICD-9-CM and ICD-10 administrative data. Med Care 2005, 43:1130-1139.

61. Rosenbaum PR, Rubin DB: The central role of the propensity score in observational studies for causal effects. Biometrika 1983, 70:41-55.

62. Austin PC: Balance diagnostics for comparing the distribution of baseline covariates between treatment groups in propensity-score matched samples. Stat Med 2009, 28:3083-3107.

63. Rosenbaum PR: Observational Studies. New York: Springer; 2010.

64. DiPrete TA, Gangl M: Assessing bias in the estimation of causal effects: Rosenbaum bounds on matching estimators and instrumental variables estimation with imperfect instruments. Sociol Methodol 2004, 34:271-310.

65. Rosenbaum PR: Sensitivity analysis in observational studies. Behavioral Science: Encyclopedia of Statistics in; 2005

66. Bundesministerium für Gesundheit (BMG) - Federal Ministry of Health: Zahlen und Fakten zur Krankenversicherung. Bonn: Bundesministerium für Gesundheit (BMG) - Federal Ministry of Health; 2012. Mitgliederstatistik KM6 - Statistik über Versicherte Gegliedert Nach Status, Alter, Wohnort und Kassenart.

67. Akobundu E, Ju J, Blatt L, Mullins CD: Cost-of-illness studies: a review of current methods. Pharmacoeconomics 2006, 24:869-890.

68. Rybczynski M, Mir TS, Sheikhzadeh S, Bernhardt AMJ, Schad C, Treede H, Veldhoen S, Groene EF, Kühne K, Koschyk D, Robinson PN, Berger J, Reichenspurner $\mathrm{H}$, Meinertz T, von Kodolitsch Y: Frequency and agerelated course of mitral valve dysfunction in the Marfan syndrome. Am J Cardiol 2010, 106:1048-1053.

69. van Karnebeek CDM, Naeff MSJ, Mulder BJM, Hennekam RCM, Offringa M: Natural history of cardiovascular manifestations in Marfan syndrome. Arch Dis Child 2001, 84:129-137.

70. Sogawa M, Ohzeki H, Namura O, Hayashi J: Preoperative respiratory physiotherapy for a patient with severe respiratory dysfunction and annuloaortic ectasia. Ann Thorac Cardiovasc Surg 2003, 9:266-269.

71. Stheneur C, Faivre L, Collod-Béroud G, Gautier E, Binquet C, Bonithon-Kopp C, Claustres M, Child AH, Arbustini E, Adès LC, Francke U, Mayer K, ArslanKirchner M, De Paepe A, Chevallier B, Bonnet D, Jondeau G, Boileau C: Prognosis factors in probands with an FBN1 mutation diagnosed before the age of 1 year. Pediatr Res 2011, 69:265-270.

72. Rybczynski M, Treede H, Sheikhzadeh S, Groene EF, Bernhardt AMJ, Hillebrand M, Mir TS, Kühne K, Koschyk D, Robinson PN, Berger J, Reichenspurner $\mathrm{H}$, Meinertz $\mathrm{T}$, von Kodolitsch $\mathrm{Y}$ : Predictors of outcome of mitral valve prolapse in patients with the Marfan syndrome. Am J Cardiol 2011, 107:268-274.

73. Blankart CR, Koch T, Linder R, Verheyen F, Schreyögg J, Stargardt T: Cost of illness and economic burden of chronic lymphocytic leukemia. Orphanet J Rare Dis 2013, 8:32.

74. Kanavos P, van den Aardweg S, Schurer W: Diabetes Expenditure, Burden of Disease and Management in 5 EU Countries. London, UK: LSE Health, London School of Economics; 2012:1-105
75. Köster I, Huppertz E, Hauner H, Schubert I: Direct costs of diabetes mellitus in Germany - CoDiM 2000-2007. Exp Clin Endocrinol Diabetes 2011, 119:377-385.

76. Huber CA, Schneeweiss S, Signorell A, Reich O: Improved prediction of medical expenditures and health care utilization using an updated chronic disease score and claims data. J Clin Epidemiol 2013, 66:1118-1127.

77. Smeets HM, de Wit NJ, Hoes AW: Routine health insurance data for scientific research: potential and limitations of the Agis Health Database. J Clin Epidemiol 2011, 64:424-430.

78. Robinson PN: Classification and coding of rare diseases: overview of where we stand, rationale, why it matters and what it can change. Orphanet J Rare Dis 2012, 7(Suppl 2):A10.

79. Orphanet: Orphanet: Prevalence of Rare Diseases: Bibliographic Data. France: Orphanet; 2014:29 [Orphanet Report Series - Rare Diseases Collection]

80. Braverman AC: Exercise and the Marfan syndrome. Med Sci Sports Exerc 1998, 30(10 Suppl):S387-S395.

81. Peters K, Apse K, Blackford A, McHugh B, Michalic D, Biesecker B: Living with Marfan syndrome: coping with stigma. Clin Genet 2005, 68:6-14.

82. Brouwer WBF, Meerding W-J, Lamers LM, Severens JL: The relationship between productivity and health-related QOL: an exploration. Pharmacoeconomics 2005, 23:209-218.

83. Lamers LM, Meerding W-J, Severens JL, Brouwer WBF: The relationship between productivity and health-related quality of life: an empirical exploration in persons with low back pain. Qual Life Res 2005, 14:805-813.

84. Rubin DB: Formal mode of statistical inference for causal effects. J Stat Planning Inference 1990, 25:279-292.

85. Taylor CM, Karet Frankl FE: Developing a strategy for the management of rare diseases. BMJ 2012, 344:e2417.

86. Von Kodolitsch $Y$, Raghunath M, Nienaber CA: [Marfan syndrome: strategies of interdisciplinary care]. Dtsch Med Wochenschr 1998, 123:21-25.

doi:10.1186/1750-1172-9-90

Cite this article as: Achelrod et al:: The economic impact of Marfan syndrome: a non-experimental, retrospective, population-based matched cohort study. Orphanet Journal of Rare Diseases 2014 9:90

\section{Submit your next manuscript to BioMed Central and take full advantage of:}

- Convenient online submission

- Thorough peer review

- No space constraints or color figure charges

- Immediate publication on acceptance

- Inclusion in PubMed, CAS, Scopus and Google Scholar

- Research which is freely available for redistribution

Submit your manuscript at www.biomedcentral.com/submit
C Biomed Central 